\title{
El arte de la vida. Wittgenstein en la encrucijada entre ética y estética
}

\author{
Carlos Nieto Blanco \\ Universidad de Cantabria, España
}

Resumen

Este artículo ofrece un aproximación al pensamiento de Witggenstein, examinando la relación que existe entre la ética y estética con el conjunto de su filosofía. El trabajo se divide en tres partes, argumentando: que la ética y la estética no se pueden expresar, pero se muestran; que la ética y la estética son trascendentales; y que la vida feliz abarca por igual a la ética y a la estética. El trabajo finaliza con un epílogo a modo de ensayo sobre la posible significación de "la casa de Wittgenstein".

Palabras clave: bondad, estética, ética, felicidad, lo místico.

\section{Abstract}

This paper offers an approach to Witggenstein's thinking, examining the relationship between ethics and aesthetics with its overall philosophy. The work is divided into three parts, arguing: that ethics and aesthetics can not be expressed, but they are shown; that ethics and aesthetics are transcendental; and that life looks equally happy to ethics and aesthetics. The work ends with an Epilogue as an essay on the possible significance of "The Wittgenstein House".

Keywords: goodness, aesthetics, ethics, happiness, the mystical. 
Le style c'est l'homme même.

BUfFON

\section{Introducción}

Gl propósito de este artículo consiste en ofrecer algunas reflexioEnes que permitan interpretar y desarrollar la parte del pensamiento de Wittgenstein que se refiere a la relación entre ética y estética, sugeridas por sus propias observaciones, y anticipadas en cierto modo en un texto anterior (Nieto, 2001), pero que se encuentran implícitas o condensadas, de un modo a veces esotérico, en la formulación más elaborada de su pensamiento. Si bien el trabajo hace especial referencia al Tractatus Logico-Philosophicus y a sus textos preparatorios, no olvida tampoco otras aportaciones posteriores a 1921, fecha de su primera edición en revista. La manera en la que al final del Tractatus queda refutada la propia doctrina filosófica que Wittgenstein se esfuerza por desarrollar a lo largo de esta obra constituye el arranque de la cuestión que nos ocupa y la que da salida a la legitimidad del problema que nos planteamos.

De acuerdo con la proposición que recoge la entrada 6.54 , todo el entramado del Tractatus se viene a bajo al aplicarle la teoría del lenguaje preposicional desarrollada en este libro. Partiendo de ella, las propias proposiciones tractarianas debieran tener otro estatuto. Tomando en consideración desarrollos más generales que hemos llevado a cabo en otro lugar (Nieto, 1997: 119-144), cabría suponer, como ya trató de sugerir en su día Bertrand Russell en su célebre Introducción a la obra, que necesitemos de una teoría sobre la jerarquía de lenguajes, pero el fuerte rechazo que su autor hizo de esta interpretación fue, como sabemos, no sólo la percep- 
ción de que su amigo había entendido de manera superficial su libro, sino también una de las causas del posterior distanciamiento entre ambos. Descartada la posibilidad de que Wittgenstein esté utilizando un metalenguaje para hablar de su propio lenguaje sólo nos queda explorar la propia vía que el autor nos sugiere en dicha proposición.

Wittgenstein dice que entender sus proposiciones significa reconocerlas como absurdas (unsinnig), pero también añade que por ese motivo sus proposiciones esclarecen (Meine Sätze erläutern), o que ese reconocimiento es precisamente causa de esclarecimiento. No es, por tanto, un resultado vacío, o un ejercicio nihilista lo que el Tractatus nos ofrece, sino todo un ejemplo de "vía negativa".

$\mathrm{Al}$ examinar un reducido elenco de proposiciones que desarrollan el número 6.4, aparecen en el horizonte otros "problemas" que carecen de solución, pero de cuya pertinaz existencia el propio Wittgenstein no sólo no quiere liberarnos, sino que, si hacemos caso a la famosa carta dirigida a su amigo Ludwig von Ficker, editor literario de la revista Der Brenner, componen la segunda parte del Tractatus, aquella "no escrita", de contenido fundamentalmente ético, y de cuyo testimonio sólo puede dar cuenta su mención, seguida del elocuente silencio que sustituye a su desarrollo (Janik y Toulmin, 1974: 211-254).

A lo largo de dichas proposiciones se menciona el sentido y el valor del mundo (6.41), se habla de la ética y de la estética (6.422), del premio y del castigo de las acciones (6.422), de la voluntad y la felicidad $(6.423,6.43)$, de la muerte y de la inmortalidad (6.4316.4312 ). En la proposición 6.432 se menciona también a Dios; en la 6.44 se introduce "lo místico", de lo que se afirma su existencia en la proposición 6.522, así como en la 6.52, y en la 6.521, este conjunto de cuestiones mencionadas entra dentro de la expresión "el problema (o los problemas) de la vida". 
Si analizamos el contenido de estos temas en el marco de la tradición filosófica observamos que encajan perfectamente dentro de la metafísica, tanto en su acepción teórica como práctica. Probablemente eso es todo lo que abarca la inquietante expresión "lo místico", con la que el filósofo vienés podría querer nombrar el sentido general de lo metafísico. Pero si descendemos un poco más en el análisis nos encontramos, sobre todo, con cuestiones de interés práctico que afectan al problema de la vida humana y su sentido, a la orientación de nuestras acciones, lo que decanta tal cuestión del lado de la ética. No sólo por ese motivo, sino por el objetivo que nos proponemos en este ensayo, en lo sucesivo pondremos el foco de nuestro análisis en las cuestiones éticas y estéticas, con especial referencia a ese nudo que, según Wittgenstein, forman ética y estética.

El fundamento para hacer un seguimiento común a la ética y la estética lo encontramos en la tercera y última línea de la proposición 6.421, donde Wittgenstein afirma: Ethik und Aesthetik sind Eins, pues como quiera que se traduzca esta expresión, todo apunta a una comunidad semántica entre ambas. ${ }^{1}$ En consecuencia, todos

${ }^{1}$ Dado lo sorprendente, entre otras cosas, por su tono enfático, de la frase en cuestión, me he permitido hacer algunas comprobaciones. La versión castellana del Tractatus por la que cito, debida a J. Muñoz e I. Reguera, traduce así "Ética y estética son una y la misma cosa" (177). La versión castellana anterior, debida a Tierno Galván, traducía como "Ética y estética son lo mismo" (Madrid, Alianza, 1973, p. 197, $1^{\text {a }}$ ed. en Revista de Occidente, Madrid, 1957). La nueva versión castellana debida a L. M. Valdés Villanueva (Madrid, Tecnos, 2002) traduce como sigue: "Ética y estética son uno y lo mismo" (269). La versión catalana, debida a J. Ma. Terricabras (Barcelona, Laia, 1981) lo vierte de este modo: "Ėtica i estètica són u”(151). En 1922, como es sabido, el texto de Wittgenstein se publica por primera vez como libro con el título que ahora tiene en edición bilingüe, en alemán y en inglés. La traducción inglesa, debida a Ogden y Ramsey, fue revisada por el propio autor, y traduce como sigue: "Ethics and aesthetics are one" (Londres, Routledge \& Kegan Paul, 1962, p. 183.) La última versión francesa, debida a G. G. Granger (París, Gallimard, 1993, p. 110) dice: "Éthique 
los predicados que podríamos atribuir a la ética convienen también a la estética. Estimo que podemos precisar esas características comunes mediante el desarrollo de estos tres argumentos:

1) La ética y la estética no se pueden expresar, pero se muestran.

2) La ética y la estética son trascendentales.

3) La vida feliz abarca por igual a la ética y a la estética.

A modo de Epílogo — que prolonga la vinculación de Wittgenstein con el mundo del arte a través de referencias biográficas-, aporto algunos comentarios sobre la posible relación de su trabajo como arquitecto de la casa de su hermana Gretl con su filosofía.

Vaya una última observación preliminar. Aunque he procurado que la prosa que empleo en este artículo sea condescendiente con el lector o lectora del mismo, la naturaleza del tema estudiado me ha llevado en ocasiones a expresarme en un estilo menos explicativo de lo que en mí es habitual, quizá por el inevitable contagio que el intérprete sufre por parte del autor que trata de dar a conocer. De este modo, si alguien encontrase algún pasaje del texto más críptico de lo habitual, o un párrafo con final más abrupto de lo acostumbrado, sepa que ello se debe no solo a la impericia del autor del artículo, sino también a lo intrincado del tema. Allí donde Wittgenstein no explica, sino que sugiere; allí donde no argumenta, sino que aporta ejemplos; allí donde no hay iluminación, sino

et esthétique sont une seule et même chose". Como puede apreciarse, frente a versiones más sobrias, predomina la insistencia en reforzar la identificación entre ética y estética. Desde mi punto de vista, sin poder aportar nada nuevo que no haya sido dicho, me parece que su sentido no es de identificación absoluta, en forma y contenido, sino que requiere una lectura contextual, es decir que el conjunto ético-estético ofrece rasgos similares, como 1) que se trata de algo que es inefable, 2) que se muestra, y 3) que posee un carácter trascendental, por lo que se podría añadir, a modo de cláusula preventiva: (En este sentido) ética y estética son lo mismo. 
chispazos ocasionales; en suma, allí donde no hay continuidad, sino fragmentariedad: en tales circunstancias difícilmente el estudioso puede suplirlo mediante un tipo de discurso completamente articulado.

\section{La ética y la estética no se pueden expresar, pero se muestran}

Este argumento tiene dos partes. La primera es negativa, y se desprende directamente de la operación de someter el lenguaje humano al canon de esa suerte de lenguaje ideal que se exhibe a través de la semántica que Wittgenstein pone en marcha en el Tractatus, la horma de su atomismo lógico, mientras que la segunda, de carácter afirmativo, es deudora de una distinción fundamental que subyace al tratamiento del complejo lingüístico, la distinción entre decir (sagen) y mostrar (zeigen).

Toda la batería de asertos sobre el lenguaje que Wittgenstein despliega en el Tractatus entra dentro del "decir". El "decir" conduce a una concepción del lenguaje que inscribe la reducción a una de sus posibles dimensiones, tomando, a modo de sinécdoque, la parte por el todo, y dando como resultado una suerte de monismo lingüístico. Mediante él se sostiene que la única manera de otorgar legitimidad al lenguaje, o el único lenguaje dotado de significado y sentido, es aquél que funciona como un conjunto de proposiciones de carácter representativo, cuya semántica pictórico-figurativo permite su engarce con el mundo a través de la figuración que representa la forma lógica con la que ambos están isomórficamente entrelazados. ${ }^{2}$

${ }^{2}$ La constatación, no justificada, sino presupuesta, de la correspondencia entre el lenguaje y el mundo puede observarse en la entrada 6.124 "Las proposiciones lógicas describen el armazón del mundo o, más bien, lo representan. No "tratan" de nada. Presuponen que los nombres tienen significado, y las proposiciones 
En la ontología del atomismo lógico que emerge de este presupuesto, aunque se distinga entre actualidad y posibilidad, entre mundo y realidad, la posibilidad de los estados de cosas que efectivamente puedan darse como hechos y constituir mundo queda sujeta a lo que permite la lógica que gobierna el lenguaje. Un lenguaje, en el que el significado de los nombres lo da la referencia a los objetos, y el sentido de las proposiciones la representación de los estados de cosas, que son conexiones de objetos. Si algo es posible como hecho lo es en virtud de la dependencia de las cosas existentes conectadas entre sí. Ni los fines, ni los deberes, ni los valores se acomodan a este lenguaje $y$, a fortiori, ninguno encuentra su lugar en esta ontología, razón por la cual no es posible con dicho lenguaje la formación de proposiciones éticas o estéticas.

Pero el lenguaje no sólo dice o expresa, sino que también muestra, o en él algo se muestra o se refleja. Lo que no puede ser representado no puede ser dicho, pero eso no significa que por carecer del estatuto lingüístico adecuado se proscriba su presencia de algún modo, en el lenguaje y fuera del lenguaje.

Lo primero que habría que decir acerca del mostrar es que mediante esta posibilidad Wittgenstein no pretende conducirnos a un idealismo de carácter lingüístico, ya que no se trata de afirmar que si algo tiene su asiento en el lenguaje, del modo que sea, por ello mismo tenga que poseer una existencia "trans" o extra-lingüística,

elementales, sentido; y ésta es su conexión con el mundo. Está claro que algo tiene que indicar sobre el mundo el hecho de que ciertas conexiones de símbolos —que tienen esencialmente un carácter determinado - sean tautologías. Aquí radica lo decisivo. Decimos que algo hay de arbitrario en los símbolos que usamos y algo hay que no lo es. En la lógica sólo esto se expresa: Pero ello quiere decir que en la lógica no expresamos nosotros lo que queremos con la ayuda de los signos, sino que en la lógica es la propia naturaleza de los signos naturalmente necesarios lo que se expresa: Si conocemos la sintaxis lógica de un lenguaje sígnico cualquiera, entonces ya están dadas todas las proposiciones de la lógica” (Wittgenstein, 1987: 157-159). 
de manera que el lenguaje por sí mismo se comprometa ontológicamente, por usar la expresión de Quine. Más bien sucede lo contrario, esto es, que algo ya existe y no puede ser dicho por no ser objeto de la representación, pero ostenta una presencia por otras vías, las del mostrarse.

De acuerdo con el Tractatus, existen tres ámbitos de realidad que se muestran. Uno es el solipsismo, otro la lógica, y un tercero "lo místico". Wittgenstein abraza el solipsismo al sostener la célebre proposición: "5.6 Los límites de mi lenguaje significan los límites de mi mundo" (Wittgenstein, 1987: 143).

Esta llamativa y abrumadora tesis no admite justificación. Para ello tendríamos que salirnos de nosotros mismos, de nuestro mundo, por tanto, de nuestro lenguaje. La proposición siguiente lo explica:

$5.62[\ldots]$ En rigor, lo que el solipsismo entiende es plenamente correcto, sólo que no se puede decir, sino que se muestra.

Que el mundo es mi mundo se muestra en que los límites del lenguaje (del lenguaje que sólo yo entiendo) significan los límites de mi mundo (Wittgenstein, 1987: 143).

Al no podernos salir de los límites de nuestro lenguaje, esta perspectiva es la única válida. Por el lenguaje se nos abre el mundo y en él se nos ofrece. El solipsismo, entonces, equivale al realismo. ¿Dónde se muestra el solipsismo? El solipsismo es la conciencia general de que ha funcionado la relación sujeto / mundo a través del lenguaje. La lógica también se muestra en el lenguaje. Veamos:

4.121 La proposición no puede representar la forma lógica; ésta se refleja en ella.

El lenguaje no puede representar lo que en él se refleja.

Lo que se expresa en el lenguaje no podemos expresarlo nosotros a través de él. 
La proposición muestra la forma lógica de la realidad.

La ostenta. (Wittgenstein, 1987: 67).

Para hablar sobre la lógica tendremos que hablar con lógica, por lo que no podemos salirnos fuera de ella. Todo posible metalenguaje que construyamos sobre la lógica tiene que ser a su vez lógico y así ad infinitum. No podemos “objetualizar” la lógica, convirtiéndola en un lenguaje objeto separable de otro lenguaje. Sea lo que fuere este segundo lenguaje, la lógica estaría en él, por lo que su posibilidad al margen de la lógica queda descartada. No es posible la autorreferencialidad, puesto que el lenguaje es representativo de lo que no es él, de algo no lingüístico, de donde se sigue que no puede desdoblarse en una representación de sí mismo, ${ }^{3}$ del mismo modo que la percepción visual ve el objeto, pero no se ve a sí misma, ni el ojo con el que vemos puede a su vez verse mientras ve.

Una proposición puede tener o no sentido. Si lo tiene, entonces puede ser verdadera o falsa, pues al convertirse en representación de los hechos, ofrece la posibilidad de mantener correspondencia o no con ellos. En caso contrario, pueden, a su vez, darse otras dos posibilidades. Puede suceder que las proposiciones sean "absurdas", como lo son las metafísicas o, por otras razones, las propias proposiciones del Tractatus, o bien que sean un "sinsentido" (sinnlos). Este último es el estatuto de las proposiciones lógicas, que nada representan, ya que sólo articulan en proposiciones complejas las posibilidades formales de verdad de las proposiciones simples, por lo que siempre son verdaderas a condición de no arriesgar ningún tipo de información sobre los hechos, lo que implica que

${ }^{3}$ La siguiente observación pone de manifiesto de forma lapidaria esta misma idea: "El límite del lenguaje se revela en la imposibilidad de describir el hecho que corresponde a una frase (que es su traducción), sin repetir justo esa frase. (Aquí tenemos que ver con la solución kantiana al problema de la filosofía)" (Wittgenstein, 1995: 45). 
son vacías. Por eso son tautologías. El perfil no representativo de las proposiciones lógicas les impide hablar de nada, como tampoco con ellas podamos decir algo acerca de sí mismas. Van con el lenguaje, a él está atada la lógica. Ni lo lógico puede representar nada, ni lo lógico, a modo de un mundo separado de "objetos lógicos", como sostuvieron en su modo Frege y Russell, puede ser objeto de representación, pues ni es un hecho, ni una posibilidad de hecho del mundo. La lógica es inseparable del lenguaje, se da en él, en él se muestra. A la postre también lo es del pensamiento, pues pensar consiste en poner en marcha la lógica del lenguaje.

Para finalizar este argumento nos falta hablar de la mostración de lo místico. Y este es un punto que afecta más directamente al objetivo de este ensayo. Lo místico es una abreviatura peculiar y problemática con la que nuestro autor se refiere a lo metafísico, como hemos indicado, por tanto a la ética y a la estética también. Dice Wittgenstein: “6.522 Lo inexpresable, ciertamente, existe. Se muestra, es lo místico” (Wittgenstein, 1987: 183).

Lo místico no puede mostrarse en el lenguaje, como veremos un poco más adelante, pues nada representa, ni permite que el lenguaje lo represente. Será otro el ámbito de la realidad por el que lo místico se ofrezca a nuestra consideración o vivencia.

Decir que lo místico es "inexpresable”, es un modo de decir que es inefable. No es nombrable, pues está fuera de la realidad prescrita por el lenguaje, pero existe. Ahí reside su peculiaridad. Ahora bien, la afirmación existencial de Wittgenstein sobre lo inefable nos pone tras la pista de su naturaleza, pues si lo místico no puede ser algo "fuera" del mundo, dado que sólo tenemos criterio para afirmar la existencia de lo que es o puede ser el caso, o - lo que no es más que el reverso lingüístico de lo mismo —admitir sólo lo que nos permiten dar a entender un conjunto de proposiciones 
con sentido - lo que descarta la existencia de algo trascendente al mundo-, tendrá que ser, ahora lo veremos, "trascendental". ${ }^{4}$

Lo místico es la parte exterior del límite, lo que está al otro lado. Lo uno no puede darse sin lo otro, como la raya fronteriza. Ahora bien, la única manera de delimitar es operando desde dentro, desde el interior de límite, pues de lo contrario tendríamos que abandonar el mundo, saliéndonos fuera del lenguaje, careciendo entonces de las posibilidades para delimitarlo.

En el escueto Prólogo al Tractatus, imprescindible para conocer sus intenciones filosóficas, Wittgenstein lo ha expresado del siguiente modo:

El libro quiere, pues, trazar un límite al pensar o, más bien, no al pensar, sino a la expresión de los pensamientos: porque para trazar un límite al pensar tendríamos que poder pensar ambos lados de este límite (tendríamos, en suma, que poder pensar lo que no resulta pensable).

Así pues, el límite sólo podrá ser trazado en el lenguaje, y lo que reside más allá del límite será simplemente absurdo (Wittgenstein, 1987:11).

La pertenencia de la ética y la estética a lo místico se desprende de las siguientes proposiciones: la 6.41, que argumenta acerca de que todo valor ha de residir fuera del mundo; la 6.421, la cual seńala la inexpresabilidad de ética y estética; así como, de modo comple-

${ }^{4}$ Como se ha recordado con frecuencia, la semejanza entre el programa kantiano y la empresa wittgensteiniana es patente, y no sólo en sus intenciones teóricas, sino en el destino que habrían de tener las cuestiones prácticas, o "lo místico”, en la terminología de Wittgenstein. Del mismo modo que Kant retira de la circulación teórica a la metafísica, pues el lenguaje que la razón teórica emplea es incapaz de entenderlo ("Tuve, pues, que suprimir el saber, para dejar sitio a la $f e$ ", $\mathrm{KrV}, \mathrm{BXXX}$.), Wittgenstein "quiso poner límites al pensamiento, para hacer lugar al sentimiento y a la voluntad” (Villoro, 1975: 35). 
mentario, la 6.44 y la 6.45 , las cuales establecen sendas conjeturas sobre lo místico como el sentimiento ante la existencia del mundo como un todo.

\section{La ética y la estética son trascendentales}

El segundo argumento precisa el carácter inexpresable de la ética y la estética, informándonos de su dimensión trascendental. Dice el autor del Tractatus:

6.421 Está claro que la ética no resulta expresable.

La ética es trascendental.

(Ética y estética son una y la misma cosa) (Wittgenstein, 1987: 177).

Sobre el significado de la palabra "trascendental", aplicado a la ética y la estética, Wittgenstein no es especialmente explícito, aun cuando en la misma obra nos diga que también la lógica es trascendental. Comenzando por la lógica, afirma nuestro filósofo: "6.13 La lógica no es una teoría sino una figura especular del mundo. La lógica es trascendental" (Wittgenstein, 1987: 161).

Sobre ello habría que decir, en primer lugar, que su carácter trascendental remite directamente al tratamiento general que Kant da a este término — no exento de alguna ambigüedad terminológica - en la Crítica de la razón pura, cuando ya en la Introducción dice textualmente: "Llamo trascendental todo conocimiento que se ocupa, no tanto de los objetos, como de nuestro modo de conocerlos, en cuanto que tal modo ha de ser posible a priori" (A12/ B25). Por tanto, remite a una acepción plenamente consagrada en el pensamiento moderno, rescatada por una parte el pensamiento contemporáneo, cuando se acude a la pertinencia del lenguaje para servir de fundamento a la ética, una ética llamada entonces "comu- 
nicativa”, "discursiva” o "dialógica”, vinculando la razón práctica con la teórica. ${ }^{5}$

La lógica es trascendental porque expresa las condiciones que posibilitan la constitución del lenguaje proposicional, legitimando su carácter representativo, convirtiéndolo, en suma, en lenguaje de pleno derecho. Como en Kant, lo trascendental —en este caso la lógica - permite la fusión de la dirección subjetiva o gnoseológica y de la objetiva u ontológica, dando lugar a un "espacio lógico" en el que se encuentran lenguaje y mundo. Lo trascendental no puede existir por sí mismo, pues es aquello que permite la aparición de lo existente para el pensamiento. ${ }^{6}$

Si ética y estética son lo mismo, y aquella es trascendental, también lo será la estética, aunque hay que reconocer que abordar esta cuestión, esto es, tratar de justificar el carácter trascendental del la ética y la estética nos enfrenta a un serio problema. Pero para dar pasos en pos de una solución habrá que ampliar el campo semántico del término en cuestión, que al asociarse a la lógica, lo impregna

${ }^{5}$ Como ponen de manifiesto los intentos de Apel y Habermas por construir, respectivamente, una "hermenéutica trascendental" o una "pragmática universal”. Véanse: Apel, K. O., La transformación de la filosofía, t. II A. Cortina, J. Chamorro y J. Conil (trad.), Madrid, Taurus, 1985, pp. 149-414, especialmente; Habermas, J., “¿Qué significa pragmática universal?”, en Teoría de la acción comunicativa: complementos y estudios previos $\mathrm{M}$. Jiménez Redondo (trad.), Cátedra, Madrid, 1989, pp. 299-368.

${ }^{6}$ Desde que en 1960 Erik Stenius propusiera una interpretación del Tractatus en clave kantiana, este tipo de lectura se ha hecho relativamente frecuente. La siguiente cita es reveladora: "En resumen: es esencial para entender la perspectiva de Wittgenstein indicar que el análisis lógico del lenguaje, concebido como un tipo de deducción trascendental en el sentido de Kant, se hace con la intención de señalar la forma a priori que se muestra en todo lenguaje significativo y, por tanto, aquello que no puede ser "dicho". Desde este punto de vista el Tractatus puede llamarse una 'Crítica del lenguaje puro' [...] Con respecto a esta teoría el sistema filosófico de Wittgenstein podría llamarse 'Lingüística crítica' o 'Lingüística trascendental' o incluso 'Idealismo lingüístico'” (Stenius, 1960: 220). 
de fuerte sentido cognitivo. Al posibilitar el carácter representativo del lenguaje, su orientación remite a la verdad, diferente del valor, que es testimonio de otro tipo de vínculos. Si queremos mantener la significación de la voz "trascendental" con un estatuto similar al de la lógica, tendremos que apelar, también en este caso, a la existencia de ciertos supuestos o condiciones que permitan la formación de los juicios de valor y que se muestren de algún modo, como en el caso de la lógica, y no resulten expresables.

Diremos que ética y estética exhiben un carácter trascendental por cuanto reclaman una dimensión del ser humano no contemplada en su exclusiva consideración epistémica. Así, del mismo modo que hay lógica si hay lenguaje con fines gnoseológicos, habrá ética y estética, si apelamos a la necesidad de actuar y de hacer. Y del mismo modo que no podemos apartarnos de las condiciones impuestas por la lógica que gobierna nuestro lenguaje, tampoco lo podemos hacer de las que rigen nuestra práctica. Ética y estética podrán ser disciplinas filosóficas, pero antes que eso ostentarán el rango de condiciones de posibilidad de la acción. Tendrán, pues, un carácter trascendental. ${ }^{7}$

Aventurándonos con Wittgenstein más allá de Wittgenstein podríamos conjeturar que el carácter trascendental que conjuntamente concierne a la ética y a la estética posee una estructura bipolar, con un polo subjetivo y otro objetivo.

Sobre el sujeto, en el Tractatus se nos dice lo siguiente:

5.641 Existe, pues, realmente un sentido en el que en filosofía puede tratarse no-psicológicamente del yo.

${ }^{7}$ En el mismo Diario, con fecha 24.7.16, Wittgenstein abunda en esta idea, escribiendo lo siguiente: "[...] La ética no trata del mundo. La ética ha de ser una condición del mundo, como la lógica. Ética y estética son uno" (Wittgenstein, 1982: 132). 
El yo entra en la filosofía por el hecho de que el "mundo es mi mundo". El yo filosófico no es el hombre, ni el cuerpo humano, ni el alma humana, de la que trata la psicología, sino el sujeto metafísico, el límite — no una parte del mundo (Wittgenstein, 1987: 146-147).

Estamos, pues, ante un yo despsicologizado, que ha perdido cualquier seña de identidad con lo humano. Wittgenstein dice que es un "límite", suscribiendo su carácter metafísico. ¿Diríamos lo mismo si afirmáramos que se trataba de una estructura trascendental? Sostenemos que así tiene que ser, porque en el contexto del Tractatus, señalarlo bajo la expresión "el mundo es mi mundo" no es otra cosa que apelar al lenguaje, como ya hemos visto. El yo trascendental es la lógica, con lo que queda cerrado el círculo del solipsismo que "abríamos" más arriba.

Por la misma razón que el yo concebido como el marco de lo lógico actúa como una condición trascendental para que los sujetos concretos puedan pensar, un yo de orden diferente podría funcionar como límite para los sujetos morales al actuar, precedente del juzgar, aunque sea a costa de quedar suspendido en el precipicio que implica la carencia de lenguaje. ${ }^{8}$

Para que se produzca el juicio de valor sobre la acción hemos de contar con las condiciones impuestas por un yo trascendental, invocado desde lo práctico, a partir de la existencia de motivos, normas y valores. Ello lo saca literalmente del mundo bosquejado por Wittgenstein, pues altera por el sentido el curso casual y causal de

${ }^{8}$ En un excelente ensayo sobre este asunto del corpus wittgensteiniano, Luis Villoro escribe lo siguiente: "De parecida manera, en Wittgenstein, la lógica es "trascendental" (6.13), porque es la condición de todo lenguaje capaz de figurar el mundo y, a su vez, no puede ser figurada por el lenguaje. Igualmente la visión del mundo como un todo limitado es condición de toda experiencia y no es, a su vez, una experiencia más. Lo místico no está, pues, "más allâ" del mundo, sino que está presupuesto en cualquier experiencia del mundo" (Villoro, 1975:18). 
los acontecimientos. Representa un límite que ve el mundo como si lo hiciese desde fuera o que se sitúa frente a él, orientándolo a partir de la interrogación sobre lo que somos capaces de hacer en él y con él. De este modo la voluntad se erige en la vía en donde se muestra este carácter trascendental de la ética y la estética. Según el Tractatus:

6.43 Si la voluntad buena o mala cambia el mundo, entonces sólo puede cambiar los límites del mundo, no los hechos; no lo que puede expresarse mediante el lenguaje.

En una palabra, el mundo tiene que convertirse entonces en otro enteramente diferente. Tiene que crecer o decrecer, por así decirlo, en su totalidad.

El mundo del feliz es otro que el del infeliz (Wittgenstein, 1987: 179).

Pero ese carácter trascendental pierde su dimensión estrictamente subjetiva, en el sentido de una cualidad propia del sujeto individual, para instalarse en una dimensión objetiva como resultado de su "inter" o trans-subjetividad.

El 7 de octubre de 1916 Wittgenstein anota en uno de sus Tagebücher, conocidos entre nosotros, como Diario filosófico (19141916), lo siguiente: "La obra de arte es el objeto visto sub specie aeternitatis; y la buena vida es el mundo visto sub specie aeternitatis. No otra cosa es la conexión entre arte y ética" (Wittgenstein, 1982: 140). ${ }^{9}$

La obra de arte y la buena vida coinciden. Estética y ética son la misma cosa en tanto que nos abren la perspectiva de la eternidad. El punto de vista de la eternidad operaría no sólo como unificador, sino también como expresión de un cierto orden trascendental que

${ }^{9}$ En el Tractatus, la entrada 6.45 dice algo muy semejante: "La visión del mundo sub specie aeterni es su visión como-todo-limitado. El sentimiento del mundo como todo limitado es lo místico" (Wittgenstein, 1987: 181). 
sitúa a la poiesis y a la praxis en su perfección, potenciando al objeto y elevando a la vida humana hasta la consumación de todas sus posibilidades.

Lejos ya de la finitud espacio-temporal, la mirada eterna articula una perspectiva no desde un lugar en particular, sino desde la conjunción de todos los ángulos que definen lo que deber ser. Es el mismo que saca al objeto y a la vida de su limitación para emplazarlo como parte de un todo en cuya trama esencial es lo que es. ${ }^{10}$ El sujeto que se arma con esta malla de carácter trascendental, a diferencia del sujeto epistémico, no sólo es el sujeto que hace y actúa, sino también el sujeto que contempla, mejor, el sujeto que se rinde a la admiración de lo contemplado por la condición de posibilidad regulativa y proyectiva que supone lo absoluto como perfección. ${ }^{11}$

En el caso de las perspectivas humanas que abren tanto la ética como la estética, lo que está en juego es la remisión a un tipo de valores absolutos (Janik, 2013: 24), vinculando ambos dominios entre sí para refutar la tesis del "arte por el arte" (Cometti, 2013: 190), de forma tal que el punto de vista de la eternidad convenga no sólo a la ética y la estética, sino la propia filosofía que destila el Tractatus, cuya lectura desde la estética cifra dicha mirada

${ }^{10}$ Como es conocido, el punto de vista de la eternidad aparece tratado por Spinoza en su Ética, constituyendo el tercer y último grado de conocimiento, propio de la sabiduría, al que llama "ciencia intuitiva". La proposición 30 de la quinta parte dice lo siguiente: "En la medida en que nuestra alma se conoce a sí misma y al cuerpo bajo una especia de eternidad, tiene necesariamente el conocimiento de Dios, y sabe que ella está en Dios y se concibe por Dios" (Spinoza, 2000: $60)$.

${ }^{11}$ En Diario filosófico, en la fecha de 30 de julio de 1916 (Wittgenstein, 1982: 134), utiliza el vocablo trascendente para referirse a la ética. Ello no nos debe inducir a pensar que estemos ante la existencia de entidades "extra" o supramundanas, que nuestro autor expresamente descarta, sino ante una forma de llamar la atención superadora de posiciones "naturalistas". 
congelando el tiempo en una "omnímoda simultaneidad" (Arenas, 2013: 108).

Para seguir con las comparaciones. El carácter trascendental de la lógica nos pone en contacto con el ser desde el momento en que aquella actúa impulsando un lenguaje representativo, bajo cuyas condiciones aparece lo que hay ante la razón. Pero además del ser está el valor, y junto a la razón está la voluntad que lo quiere. El carácter trascendental de lo ético y estético opera bajo otros supuestos que lo lógico, y su presencia es refractaria a una mostración lingüística. Lo místico ahora se muestra en la vida, en lo conativo - frente a lo cognitivo- en el sentimiento ante lo que hay, pero a la espera de lo que puede y debe haber. ${ }^{12}$ La toma de conciencia de esta última posibilidad no desarrollada por el propio Wittgenstein, en abierto contraste con el tratamiento que dispensa a la lógico, podría servir a modo de unos "prolegómenos" a toda ética y estética futuras (véase Salmerón, 1992).

\section{La vida feliz abarca por igual a la ética y a la estética}

En primer lugar, la felicidad está en la base de la ética. De acuerdo con el comentario del propio Wittgenstein, la obediencia al deber que toda acción moral comporta conduce a la felicidad, punto y

${ }^{12}$ Isidoro Reguera escribe lo siguiente: "Parece lógico y natural que los sentimientos e intuiciones constituyan también el mundo, como pone de relieve la misma expresión wittgensteiniana: "el mundo del feliz" o "el mundo del infeliz". Y, con ello, que existiera una especie de mística de la trascendentalidad, al lado de la lógica. Muy parecida a la práxica del segundo Wittgenstein, por cierto: una constitución o posibilidad de conocimiento no lógico pero apriórico del mundo, es decir, una posibilidad de valoración apriórica del mundo desde el sentimiento o la intuición, desde prácticas humanas como esas, que funcione desde otras perspectivas humanas que no son las categorías lógicas o las científicas. [...] En la vida práxica del segundo Wittgenstein y en la vida mística del primero" (Reguera, 2002: 131). 
seguido a la pregunta de por qué tengo que hacer lo que debo. No puedo esperar un premio ańadido a mi acción, a modo de un sistema de recompensas, pues en ese caso, de acuerdo con la advertencia de Kant, estaría condicionando el deber a otras hipótesis ajenas al mismo, con lo que decaería el desinterés que es propio de la acción moral, rasgo que forma parte de la esencia de su nobleza. Si hay premio, y el premio parece que tiene que consistir en algo agradable, éste se encuentra en la práctica de la propia acción. Hacer lo que debo es mi premio. ${ }^{13}$

Como por otro lado lo que debo hacer es lo que está bien, se sigue de ahí que tanto la bondad como el sentimiento que acompaña a su práctica se encuentren en la propia acción hecha por deber: es buena y me hace feliz (me premio haciéndola), es buena porque me hace feliz, y soy feliz si actúo bien. Lo cual no le impide a Wittgenstein reconocer que se encuentra ante un misterio, ya que no puede convertir a ninguno de los términos de la ecuación

${ }^{13}$ Esta misma idea, como es sabido, fue defendida por Spinoza. La última proposición de su Ética $(5,42)$ sostiene que "La felicidad no es el premio de la virtud, sino la virtud misma; ni gozamos de ella porque reprimamos las concupiscencias, sino que, al contrario, porque gozamos de ella, podemos reprimir las concupiscencias" (Spinoza, 200: 268). Por lo que se refiere a Kant habría que decir que se mueve en un línea semejante, un trayecto que iría del filósofo holandés hasta Wittgenstein pasando por Königsberg. Sin embargo, en alguna ocasión Kant ha dado la impresión de albergar a un cierto "eudaimonista metafísico", si nos atenemos a los pasajes finales de su primera Crítica, aquellos que se refieren al "Canon de la razón pura". Cuando trata de explicar el sentido de su famosa tercera pregunta "¿Qué puedo esperar" (si hago lo que debo)? apela a la esperanza racional que nos asiste a ser felices — si no aquí, sí en el otro mundo- si hemos obrado como debemos, con lo que establece una relación de consecuencia entre moralidad y felicidad, lo que le permite hablar de "una moral autorrecompensadora" (Véase $K r V$, A810/B838). 
"bueno igual a feliz" en causa o consecuencia del otro. No hay, pues, fundamentación. ${ }^{14}$

Así lo pone de manifiesto en su Diario con fecha del 30 de julio de 1916:

[... Una y otra vez vuelvo sobre ello: la vida feliz es buena, la infeliz mala. Simplemente. Y si ahora me pregunto por qué he de vivir yo precisamente feliz, la cuestión se me presenta como meramente tautológica; parece que la vida feliz se justifica por sí misma, que es la única adecuada (Wittgenstein, 1982: 134).

En segundo lugar, la felicidad asoma también por los caminos de la estética. En el Diario, otra vez el 7 de octubre de 1916, dice: "[...] Es arte es una expresión. La buena obra de arte es la expresión consumada" (Wittgenstein, 1982: 140). Expresión, pero no por el lado de lo que expresa sino de cómo lo expresa, no por el ajuste representativo que conduce a la verdad de la expresión, sino por el código expresivo que lleva a la belleza ( $¡ y$ acaso también de un sujeto que se expresa en la obra creada al modo de la aportación de la estética romántica?) Pero para que podamos hablar de arte tenemos que darnos de bruces con lo bien hecho, "con la expresión consumada", con lo bello, con lo "hermoso", como dirá más adelante. "Y lo hermoso — añade— es, precisamente, lo que hace feliz" (Wittgenstein, 1982: 145). ¿Y no podríamos considerar a la

${ }^{14}$ Con fecha del 30 de julio de 1916 escribe: “[...] Está claro, de todos modos, que la ética nada tiene que ver con castigo y premio. Esta cuestión acerca de las consecuencias de una acción ha de carecer, pues, de importancia. Por lo menos estas consecuencias no pueden ser acontecimientos. Porque algo justo tiene que haber, de todos modos, en aquel planteamiento. Debe haber, ciertamente, un tipo de premio y de castigo éticos, sólo que éstos han de radicar en la acción misma.

“ [...] Y está claro también que el premio ha de ser algo agradable, y el castigo algo desagradable" (Wittgenstein, 1982: 133-134). 
ética, también bajo el signo de la expresión, como el mostrase la vida por medio de ejemplos modélicos?

Hemos llegado a una nueva ecuación: "bello es igual a feliz". Aplicando una elemental transitividad lógica, concluiremos que ética y estética vuelven nuevamente a encontrarse por los derroteros de la felicidad, puesto que si lo bueno y lo bello es lo que nos hace felices, la felicidad es aquello que las equipara, en lo que coinciden.

La felicidad atiende a dos posibles requerimientos. Es, por un lado, el resultado de una vivencia de plenitud cuando nos reconocemos autores de lo que está bien hecho, obrando bien y produciendo la obra de arte, creando, en suma. En tal caso la experiencia de la felicidad procede de nuestra condición de sujetos activos. Somos felices por y con lo nuestro. Por otro lado, podemos ser sujetos pasivos de la misma, pues el estado de felicidad no nace ahora de lo hecho por nosotros mismos sino que emerge del espectáculo que supone la contemplación del mundo. Contemplar lo que existe con ojo feliz expresa el regocijo y el disfrute que emana de dicha visión cuando la sorpresa por lo que hay nos envuelve al sentirnos en empatía y armonía con el mundo, fundidos con él, en él sumergidos. Es lo otro lo que nos hace felices. Así lo expresa nuestro autor: “[...] El milagro estético es la existencia del mundo. Que exista lo que existe. ¿Es la esencia del modo de contemplación artística contemplar el mundo con ojo feliz?” (Wittgenstein, 1982: 145).

Desde esta óptica, la conjunción o el bucle ético / estético se ve más claro y, a falta de ulteriores precisiones, no parece descabellado sostener que para Wittgenstein el paradigma estético podría convertirse en guía del ético, lo que sería una manera de reinterpretar bajo dicha clave ese fondo estoico y spinoziano por el que con fre- 
cuencia se mueven sus convicciones éticas. ${ }^{15}$ La plenitud va unida al gozo, y la belleza aparece como señal, como síntoma de bien. El arte de vivir convierte a la vida en obra de arte cuando todo es como debe ser. ${ }^{16}$

A comienzos de 1930 Wittgenstein pronunció una conferencia que fue publicada por primera vez en 1965 con el título Lecture on Ethics. Que sepamos, ésta fue la última vez que nuestro autor que había retornado por aquellas fechas a la filosofía después de la azarosa "travesía del desierto" que emprendiera tras la publicación del Tractatus_, se ocupó, al menos académicamente, de cuestiones éticas, las cuales giran hacia el territorio religioso en los años posteriores, sin que progrese la teoría, sólo los ejemplos (Barrett, 1994: 297-322). ¿Qué aporta esta conferencia a lo que ya conoce-

${ }^{15}$ A pesar de que Wittgenstein considere a la estética como parte de la ética (Wittgenstein, 1989: 34), creemos que el modo de presentar aquella otorga supremacía al momento estético. J. C. Edwards sigue en esto literalmente a Wittgenstein, introduciendo la expresión "ética del amor (love)", o de la admiración, lo que hace distinguiendo entre una actitud "metafísica" que se sitúa ante el mundo como frente a un acertijo y otra actitud, como sería el caso de Wittgenstein, "mística", que lo trata de modo reverente (Edwards, 1982: 237 y ss.). Pero fijándonos no sólo en el texto, sino también en el contexto y hasta en el "subtexto" wittgensteiniano, estaríamos autorizados a pensar que la rendida admiración por lo que hay, así como por la perfección de la obras, la sorpresa por lo que existe y por lo que se produce, impregna lo ético de un fuerte sentimiento "estético".

${ }^{16}$ En un artículo publicado al final de su vida, el pensador español José Ferrater Mora - que había llamado la atención de la comunidad filosófica internacional en 1949 con una de las primeras y más originales contribuciones al conocimiento de la obra de Wittgenstein (Ferrater Mora, 1967), artículo que pasó por diferentes títulos y lenguas a lo largo de los años siguientes (véase Nieto, 2011) considera que la concepción del arte de nuestro autor es deflationary. Con ello se refiere al hecho de que, si bien en el Tractatus reserva un trato especial para determinadas obras de arte que son objeto de admiración, y no de lenguaje, en su última etapa trata la producción artística de un modo más compaginable con el resto de actividades humanas (Ferrater, 1993: 137-139). 
mos? Nada, si nos atenemos a los presupuestos teóricos, que son los mismos del Tractatus, de los que no se aparta lo más mínimo; algo, sin embargo, si consideramos el lugar desde el que habla. Esta atalaya es su propia persona, algunas de cuyas experiencias cuenta al auditorio para orientar lo que quiere decir. Desde nuestro punto de vista, las conclusiones más importantes de este texto son las siguientes:

Las cuestiones de carácter ético tienen una estructura similar a las de carácter estético.

Los juicios de valor de carácter ético remiten a un bien absoluto que deberíamos poner en práctica, pero tal absoluto no encuentra ningún acomodo en las redes del lenguaje.

En consecuencia, los únicos juicios de valor que podemos hacer son relativos, pero éstos se reducen a enunciados de hecho, y "ningún enunciado de hecho puede nunca ser ni implicar un juicio de valor absoluto" (Wittgenstein, 1989: 36).

La manera más adecuada de aproximarnos a las cuestiones éticas sería por medio de ejemplos que describan vivencias, o mediante el uso de comparaciones y símiles, en suma, por medio de un lenguaje alegórico.

Pero todo ello se queda en el aire al reconducirlo a los dominios de un lenguaje significativo, pues nada podemos decir de aquello que está tras el símil al no formar parte de los hechos del mundo.

La ética no es, pues, una cuestión natural, sino "sobrenatural" (Wittgenstein, 1989: 37), para la que no hay lenguaje posible, no por defecto en el mismo, sino por falta de sentido de la cuestión, a pesar de lo cual la ética merece profundo respeto.

Las palabras con las que se pone fin a su exposición son, a este respecto, toda una declaración de principios. Así concluye:

Mi único propósito - y creo que el de todos aquellos que han tratado alguna vez de escribir o hablar de ética o religión- es 
arremeter contra los límites del lenguaje. Ese arremeter contra las paredes de nuestra jaula es perfecta y absolutamente desesperanzado. La ética, en la medida en que surge del deseo de decir algo sobre el sentido último de la vida, sobre lo absolutamente bueno, lo absolutamente valioso, no puede ser una ciencia. Lo que dice la ética no añade nada, en ningún sentido, a nuestro conocimiento. Pero es un testimonio de una tendencia del espíritu humano que yo personalmente no puedo sino respetar profundamente y que por nada del mundo ridiculizaría (Wittgenstein, 1989: 43).

La inseguridad a la que nos arroja la falta de lenguaje no nos libera de la inexorable necesidad de actuar ni de buscar la forma de justificarnos. Antes de Wittgenstein ya sabíamos que la filosofía no era una ciencia. Pero las aporías a las que nos conduce una parte de su pensamiento, al tiempo que cierran el paso a la teoría, lo abren para la práctica, para el reconocimiento de que no hay más solución que la acción, la cual está sometida a otros registros.

\section{Epílogo: "Ludwig Wittgenstein. Arquitecto"}

Efectivamente, "el estilo es el hombre", como nos recordaba el naturalista ilustrado Buffon en la entrada de este artículo. Y de nadie mejor que de Wittgenstein podrá afirmarse que poseía ese estilo tan singular que lo convirtió en un hombre genial. El modo cómo se cruzan, influyen y amalgaman todos los resortes humanos para conformar el estilo de una personalidad como la suya se explaya en la naturaleza del bucle ético / estético que acabamos de analizar. Pero nada de ello hubiera sido posible sin el concurso de un carácter tan poliédrico como el de Ludwig Wittgenstein, que experimentó consigo mismo actividades tan esquivas entre sí como la ingeniería aeronáutica, la filosofía, el oficio de soldado, la enseñanza primaria, la arquitectura, la jardinería, la vuelta a la filosofía, y los auxilios sanitarios. Como tampoco hubiera podido emerger 
semejante riqueza de vivencias de no mediar el talente moral y la pasión por las artes puestos en juego por su protagonista.

Algunos aspectos más íntimos de la vida Wittgenstein han llegado hasta nosotros gracias al progresivo descubrimiento que hemos ido teniendo no solo de las aportaciones teóricas que figuran en sus obras póstumas, sino de las jugosas noticias y reflexiones contenidas en sus diarios. Su vida personal no fue ajena a la familia donde Wittgenstein nació, creció, huyó y volvió, pero con la que siempre mantuvo más que un vínculo emocional. Para decirlo de forma abrupta, la familia al frente de la cual estaba el patriarca Karl Wittgenstein, quizá el hombre más rico del imperio austrohúngaro, estaba integrada, además de por los dos padres, por ocho hijos vivos, pero tanto unos como otros usufructuaban personalidades complejas desde el punto de vista psicológico, con una fuerte excitación nerviosa casi permanente, rayana en ocasiones en lo patológico, al punto de que a tres de los vástagos la vida se les hizo insoportable, sin que el propio Ludwig descartara en algunos momentos la idea del suicidio. Dado el fuerte carácter del padre, Karl, que nuca encontró aposición por parte de la madre, como fue el caso de su compañera Leopoldine, la familia Wittgenstein, hasta que los hijos fueron lo suficientemente independientes, vivió atormentada por un padre autoritario, obsesionado con que sus cinco hijos varones ocuparan los puestos de responsabilidad en la industria del acero, los negocios y la banca de los que él se retiró tras amasar una inmensa fortuna. Como nos dice el autor de la obra La familia Wittgenstein:

Al igual que muchos hombres consagrados al comercio [Karl] tenía un conocimiento muy superficial de los factores psicológicos que operaban en su familia y solo era capaz de valorar a sus hijos comparando sus logros con los propios. Si demostraban tener menos energía que él, ser menos capaces y menos valientes, o estar menos dispuestos a asumir riesgos, consideraba que habían fraca- 
sado. La presión a la que sometió a sus hijos varones (Hans, Kurt, Rudi, Paul y Ludwig) para que dejaran su huella en el fabuloso negocio del hierro, el acero, las armas y la banca que él había erigido contribuyó a generar un tensión nerviosa y autodestructiva en los cinco (Waugh, 2009: 62).

Ninguno de los hijos siguió el designio al que su padre había querido destinarlos, y todos ellos, hijos e hijas, padre y madre, a pesar de sus diferencias, desarrollaron un talento excepcional para la música, pues eran capaces de ejecutar juntos y por separado cualquier partitura al piano, violín u otros instrumentos de viento. Paul Wittgenstein, que ya había debutado como pianista antes de la Guerra del 14, tras perder el brazo derecho en la contienda, alcanzó fama internacional como concertista de piano con la mano izquierda, para la que hizo que le escribieran algunos conciertos notables compositores del momento, como el propio Maurice Ravel.

La munificencia del padre y de algunos de sus hijos, incluido el propio Ludwig, fue decisiva para apoyar a músicos y artistas de aquella Viena fin de siècle, pues, al tiempo que por la Musiksaal del suntuoso palais en que los Wittgenstein tenían su residencia, situado en la Alleegasse de la capital del imperio, desfilaba la flor y nata de la música vienesa, la familia alcanzó notoriedad en las funciones de mecenazgo, situándose en el centro de la cultura de la época por sus apoyos.

Tras pasar seis años como maestro de enseñanza primaria en dos aldeas de la Baja Austria, Ludwig regresó a Viena en 1926, donde su hermana Margarette - apodada familiarmente Gretl, que había cambiado su apellido de soltera al casarse con el norteamericano Jerome Stonborough — , se estaba haciendo construir una casa, ubicada en el número 18 de Kundmanngasse, que hoy todavía sobrevive, pero como un centro cultural de Bulgaria. Junto a Paul y a Ludwig, Gretl fue la única hermana que se interesó vivamente 
por la cultura de su tiempo, ampliando su formación científica y relacionándose con las personalidades más relevantes del momento, facilitando a su hermano, el filósofo, contactos con el entorno intelectual de su ciudad. Había encargado al arquitecto y amigo de la familia Paul Engelmann, también de origen judío, el proyecto de la misma, pero pidió su hermano ayuda para colaborar en la tarea. El resultado es de sobra conocido, pues, respetando el diseño original que Engelmann había elaborado, Wittgenstein acabó por desplazar a su amigo de la empresa, convirtiéndose en director único del proyecto constructivo, al punto de que la obra de la mansión de su hermana ha pasado a la historia como una obra "suya", conocida como "la casa de Wittgenstein", lo que permitió a su flamante autor hacerse imprimir unas tarjetas de visita con el nombre de "Ludwig Wittgenstein. Arquitecto".

Esta información sobre la actividad arquitectónica de Wittgenstein estaría fuera de lugar y no dejaría de consistir en una pintoresca anécdota biográfica, si no se refiriese a un pensador para quien, como acabamos de ver, la estética ocupó un lugar significativo en el seno de sus inquietudes filosóficas. Esto sí que es de todo punto singular, puesto que quien fue capaz de reflexionar sobre el arte era la misma persona que poseyó un talento extraordinario para la música -memorizando partituras e interpretando distintos instrumentos-, además de haber dirigido con entrega y dedicación exclusiva - minuciosa y obsesiva - la construcción de un edificio - sin que su autor seguramente lo pretendiese — situado en la vanguardia estilística del siglo XX.

Mucho se ha escrito y más aún especulado acerca de la posible relación que pudiera existir entre la filosofía de Wittgenstein y la casa de la calle Kundmanngasse construida para su hermana, pues, a fin de cuentas, se pensaba, alguna afinidad tendría que haber entre ambas contribuciones si nacieron de la misma mente. Wittgenstein trabajó intensamente en la casa desde el otoño de 1926 
hasta la misma estación de 1928, partiendo para Cambridge en enero del año siguiente, retornando de nuevo a la filosofía. Hasta 1928, nuestro filósofo había publicado tres de los cuatro textos que dio a la luz mientras vivió: en 1912 una brevísima recensión sobre un libro de lógica; en 1922 el Tractatus como libro; en 1926 su Diccionario para alumnos de escuelas primarias (Wörterbuch für Volkschulen), concebido con la intención de facilitar el aprendizaje de la ortografía a sus estudiantes, para lo cual seleccionó un elenco de términos restringido al uso de aquellos, como señala en el Prefacio de la obra (Wittgenstein, 1997: 37-43). Por lo pronto, dado que el filósofo vienés todavía tardó varios años en hacer explícitos los profundos cambios que sufriría su pensamiento filosófico en su segunda etapa, deberíamos confinar la comparación, caso de hacerlo, a la filosofía que figura en el Tractatus Logico-Philosophicus, aunque, si lo hiciéramos, seguramente nos encontraríamos con el desmentido de su autor.

La mansión de cuya construcción Wittgenstein se sentía orgulloso muestra en el exterior un conjunto de tres cuerpos anexos con alturas diferentes, cuya geometría rectilínea se ofrece por medio de volúmenes en forma de prismas cuadrangulares, a modo de factura "cubista", con muros totalmente lisos, ayunos de cualquier elemento decorativo. Se ha señalado que hasta aquí había llegado el propio Engelmann, responsabilizándose Wittgenstein por completo del diseño del interior de la casa, y puesto que aquél fue discípulo de Adolf Loos, uno de los renovadores de la arquitectura vienesa de comienzos del siglo XX - y de paso uno de los creadores de la arquitectura "moderna" - , se ha querido ver en el edificio del que hablamos la influencia loosiana, y, por tanto, ubicar la casa de Wittgenstein en el marco de las arquitecturas racionalistas y funcionalistas de nuestra época. Ello representaría un esfuerzo por huir de la estética historicista, como quien reniega de su propio mundo, sin saber que ese retorno a formas más puras y austeras 
era más una mirada hacia futuro que un regreso al pasado. Por lo tanto, fuese o no por influencia de Loos, tanto el arquitecto como quien aspiraba a considerarse como tal, podrían haber estado pensando, en la que medida que las contemplaban de forma opuesta, más en la utilidad del producto que en su belleza ${ }^{17}$.

Pero, con independencia de las intenciones de su creador Wittgenstein en este caso- a nadie le está prohibido dejar que sus ojos se dirijan al edificio movidos por el impulso estético, si lo que tiene ante sí ejerce una atracción sobre él. Por ese motivo, si penetramos en el interior de estancia examinando los efectos de la luz, comprobando los colores de los paramentos y la distribución de las puertas, pero observando también el funcionamiento de las cortinas metálicas y el diseño de los radiadores, junto a preguntas sobre su funcionalidad, es probable que en nosotros se despierten también sensaciones y emociones relacionadas con la admiración, o, al menos, con el asombro. $Y$ en ese momento donde alguien que ha leído el Tractatus puede, a su vez, preguntarse por la relación que guarda su filosofía con lo que está viendo. Desde nuestro punto de vista, más allá de darle la vuelta a la cuestión y otorgar un valor "estético" a la arquitectura del Tractatus, se hace difícil descubrir un sentido "filosófico" a la casa, a no ser que la austeridad, el laconismo y hasta el tono lapidario con que de forma tan concentrada vienen expresadas las proposiciones tractarianas, se presenten como fundamento del detallismo, la contención y la simplicidad de las

${ }^{17}$ En un artículo reciente sobre el tema — que califica la aportación de nuestro autor a la arquitectura como de "racionalismo constructivo"-, y dado que el trabajo de Wittgenstein se concentró fundamentalmente en el interior de la casa, se descarta que el filósofo estuviese influido por la estética de Adolf Loos, pues a diferencia de que lo en éste era habitual, nuestro filósofo empleó piedra artificial de color negro antracita para los suelos de la planta principal — que en combinación con la luz que penetra desde el exterior produce un cierto efecto de "desmaterialización"-, construyendo en metal puertas y ventanas, dando como resultado una solución de tipo "maquinista"( Sarnitz, 2013: 227-311). 
formas arquitectónicas, sumiendo a quien se detiene en el interior de la casa como espectador en la misma sensación de respeto, perplejidad y hasta del silencio que obtiene el lector que ha llegado hasta la entrada 7 del Tractatus, tras doblar todas las anteriores. Ahora bien, este paralelismo no puede ir mucho más lejos, puesto que como arquitecto, Wittgenstein estaba tratando de levantar una casa "habitable" para su hermana y su familia — a pesar de las protestas de Gretl sobre los onerosos caprichos arquitectónicos de su hermano-, mientras que como filósofo se había encargado de poner una potente carga explosiva en su propia obra filosófica con la penúltima entrada, que acabó por hacerla inhabitable.

¿Tenía el protagonista de esta historia alguna opinión al respecto? En el inédito mecanografiado conocido como Big Typescript, número $213, \$ \$ 89-93$, parágrafos dedicados a la filosofía, dice lo siguiente: "El trabajo en filosofía es justamente más —como muchas veces el trabajo en arquitectura - el // un // trabajo sobre uno mismo. Sobre la propia concepción. Sobre cómo ve las cosas uno (Y lo que se reclama de ellas.)" (Wittgenstein, 1997b: 172).

En este punto Wittgenstein homologa la arquitectura a la filosofía desde un criterio "expresionista", como tipos diferentes de creatividad en los que es el propio sujeto el que se expresa o manifiesta, diciendo: este soy yo, alguien reconocible, aquí estoy, pero de modo muy diferente, pues en un caso lo hago como filósofo y en otro como arquitecto. Dicho lo cual, la relación entre ambas disciplinas se desvanece, si es que alguna vez la hubo. Y la razón por la que la relación entre las dos no va más allá es por la autonomía de que gozan ambos tipos de discurso, el filosófico y el arquitectónico, de modo que la arquitectura es un gesto que requiere contemplación, quizá admiración, tras lo cual se esconde su dueño.

Desde el punto de vista interno, Wittgenstein era consciente del carácter reproductor de su trabajo en la construcción de la casa, 
como obra transportada a la región estética, explicándolo de dos maneras. En primer lugar, comparándolo con la música de Mendelssohn y con el pensamiento de Kierkegaard, se reconoce en ellos en la ausencia de "profundidad", en que falta el "animal salvaje", y se nombra, igual que a ellos, "artista reproductivo", cuando escribe en 1940: "En el mismo sentido: es mi casa para Gretl el producto de una decisiva agudeza auditiva, buenas maneras, la expresión de una gran comprensión (para una cultura, etc.). Pero falta la vida primigenia, la vida salvaje que quisiera desfogarse" (Wittgenstein, 1986: 75).

En segundo lugar, la autoconciencia estética de nuestro autor respecto de su obra arquitectónica es el resultado de interpretar su creatividad restringiéndola sólo al uso de un nuevo lenguaje, pero reproduciendo un viejo estilo (Wittgenstein, 1986: 108-109). Es, por lo tanto, un apreciación más modesta de lo que podría deducirse a tenor de los comentarios que su obra ha suscitado, aunque a lo mejor no pueda ir mucho más allá la novedad de las obras consideradas o presentadas como realmente "nuevas".

Si hubiera que avanzar en la comparación de la filosofía con la obra de arte, juntando de nuevo el Tractatus con la casa, tendríamos que abundar en los procedimientos que exhiben uno y la otra, y ahí sí que las fronteras se tornan en aristas. Consideremos la posibilidad que ambos tienen desde el punto de vista explicativo. El código lingüístico de la obra filosófica permite construir la explicación de una idea mediante la formulación de un nuevo enunciado que sustituya al antiguo, porque dice lo mismo. En la obra de arte no existe esa posibilidad de sustituibilidad, porque mientras el texto filosófico remite al comprender, la obra de arte ser resume en el ver (Cometti, 1998: 33-37), lo que nos lleva a concluir que en el arte no hay explicación posible. Avanzando hacia lo que el propio Wittgenstein diría en sus Investigaciones filosóficas escritas en 1943, la arquitectura es otro "juego de lenguaje" (Carmona, 
2012: 339-340) — que es manifestación de una "forma de vida"-, al parecer imparangonable con el juego de lenguaje propio de la filosofía, aunque nuestro autor nunca estuvo dispuesto a dispensar tal cualidad al discurso filosófico.

Pero la enjundia de todo este asunto reside en tomar conciencia de que el autor de ambos juegos es el mismo jugador, que se ha permitido hacer filosofía y arquitectura, y que ha trazado una reflexión que conduce por derroteros similares al mundo de la ética y de la estética, allí donde, mejor que en otro sitio, habita el ser humano.

\section{Fuentes primarias}

Wittgenstein, L., 1982, Diario filosófico (1914-1916), J. Muñoz e I. Reguera (trad.), Barcelona, Ariel.

, 1984, Werkausgabe in 8 Bänden, Farnkfurt am Main, Suhrkamp.

, 1986, Observaciones, G. H. von Wright (ed., con la colaboración de H. Nyman), E. C. Frost (trad.), México, Siglo XXI.

, 1987, Tractatus Logico-Philosophicus, texto en alemán y en castellano, J. Muñoz e I. Reguera (trad. e intro.), Madrid, Alianza.

, 1988a, Investigaciones filosóficas, texto en alemán y en castellano, A. García Suárez y C. Ulises Moulines (trad.), Barcelona, Crítica.

, 1988b, Sobra la certeza, texto en alemán y en castellano, G.E.M. Anscombe y G.H. von Wright (comp.), J.Ll. Prades y V. Raga (trad.), Barcelona, Gedisa.

, 1989, Conferencia sobre ética, F. Birulés (trad.), M. Cruz, (intro.), Barcelona, Paidós. 
, 1992a, Lecciones y conversaciones sobre estética, psicología y creencia religiosa, il. Reguera, (trad. e intro.), Barcelona, Paidós.

, 1992b, Observaciones a La rama dorada de Frazer, J. Sádaba (intro. y trad.), J. L. Velázquez (ed. y notas), Barcelona, Ariel.

, 1995, Aforismos. Cultura y valor, E. C. Frost (trad.), J. Sádaba (pról.), G.H. Von Wright (prefacio), Madrid, EspasaCalpe. sini (trad.), México, UNAM.

1997a, Observaciones filosóficas, R. Rhes (ed). A. Toma, 1997b, Ocasiones filosóficas 1912-1951, J. C. Klagge y A Nordmann (ed.), A. García Rodríoguez (trad.), Madrid, Cátedra.

\section{Fuentes secundarias}

Arenas, L., 2013, "A lo que el arte debe apuntar: el Tractatus y el ideal de la obra de arte en el joven Wittgenstein", en Marrades, J. (ed.), Wittgenstein: Arte y Filosofia, Madrid, Plaza y Valdés, pp. 101-117.

Attala, D., 2002, "Wittgenstein contra la explicación. Comentarios a las observaciones de Wittgenstein sobre Frazer", Er. Revista de Filosofía, núm. 31, pp. 97-132.

Barret, C., 1994, Ética y creencia religiosa en Wittgenstein, H. Marraud González (trad.), Madrid, Alianza.

Bouveresse, J., 1993, Wittgenstein y la estética, ed. de dos capítulos de la obra del mismo autor Wittgenstein: la rime y la raison, París, E. De Minuit, 1973, pp. 153-234, J. J. Marzal y S. Rubio (trad., intro. y notas), Valencia, Universitat de València. 
Carmona Escalera, C., 2012, "De un caso paradigmático de las relaciones entre filosofía y arte. 'La casa de Wittgenstein': un trabajo de clarificación", Estudios filosóficos, núm. LXI, pp. $317-$ 340.

Commetti, J. P., 1998, La maison de Wittgenstein, París, PUF. , 2013, "Wittgenstein y el arte del siglo XX. Pensar con Wittgenstein contra Wittgenstein”, C. Ors (trad.), en Marrades, J. (ed.), Wittgenstein: Arte y Filosofía, Madrid, Plaza y Valdés, pp. 179-195.

Edwards, J. C., 1982, Ethics Without Philosophy. Wittgenstein and the Moral Life, University Press of Florida.

Ferrater Mora, J., 1967, "Wittgenstein o la destrucción”, en Obras selectas, II, Madrid, Revista de Occidente, pp. 225-235.

, 1993, "Deflationary Art", en J. M. Terricabras (ed.), A Wittgenstein Symposium. Girona, 1989, en Studien zur Österreichischen Philosophie (Hrausgegeben von R. Haller), Band XVIII, pp. 129-139.

Gargani, A. G., 1986, "Ethics and the Rejection of Philosophical Theoriziting in Wittgenstein and in Austrian Culture", en Nyíri, J. C. (ed.), Von Bolzano zu Wittgenstein (Schriftenreihe der Wittgenstein-Gesellschaft), Band 12/2, Hölder-Pihler-Tempsky, pp. 183-194.

Giner, S., 2012, El origen de la moral. Ética y valores en la sociedad actual, Madrid, Alianza.

Hierro S. y J. Pescador, 1966, "La ética en Wittgenstein”, Aporía, núm. 7-8, pp. 251-263.

Janik, A. y St. Toulmin, 1974, La Viena de Wittgenstein, I. Gómez de Liaño (trad.), Madrid, Taurus.

Janik, A., 2013, "Wittgenstein, la ética y el silencio de las musas" C. Ors (trad.), en J. Marrades (ed.), Wittgenstein: Arte y Filosofia, Madrid, Plaza y Valdés, pp. 17-44. 
Kant, I, 1978, Critica de la razón pura, P. Ribas (ed. y trad.), Madrid, Alfaguara.

McGuinness, B. F., 1966, “The Mysticism of the Tractatus”, Philosophical Review, núm. 75, pp. 305-328.

, 1991, Wittgenstein. El joven Ludwig (1889-1921), H. Marraud (trad.), Madrid, Alianza.

Monk, R., 1994, Ludwig Wittgenstein. El deber de un genio, D. Alou (trad.), Barcelona, Anagrama.

Muguereza, J., 1992, “Las voces éticas del silencio”, en Castilla del Pino, C. (ed.), El silencio, Madrid, Alianza, pp. 125-164.

Nieto Blanco, C., 1997, La conciencia lingüistica de la filosofía. Ensayo de un crítica de la razón lingüistica, Madrid, Trotta.

, 2001, "La claridad en penumbra: Wittgenstein cincuenta años después”, Trasdós, núm. 3, pp. 119-149.

Reguera, I., 1994, El feliz absurdo de la ética (el Wittgenstein místico), Madrid, Tecnos.

, 2002, Ludwig Wittgenstein. Un ensayo a su costa, Madrid, Edaf.

Rubio Marco, S. y J. J. Marzal Felici, 1993, "Los cimientos de un castillo en el aire”, en V. Sanfélix Vidarte (ed.), Acerca de Wittgenstein, Valencia, Universitat de València, pp. 161-170.

Sádaba, J., 1984, Lenguaje, Magia, Metafísica (El otro Wittgenstein), Madrid, Libertarias.

, 1989a, "Ética analítica”, en V. Camp (ed), Historia de la ética, t. III, Barcelona, Crítica, pp. 163-220.

, 1989b, La filosofía moral analitica: de Wittgenstein a Tugendhat, Madrid, Mondadori.

Salmerón, F., 1992, "Los orígenes de la filosofía moral analítica a partir de Moore y Wittgenstein”, en V. Camps, O. Guariglia O. 
y F. Salmerón (eds.), Concepciones de la ética, v. 2, Enciclopedia Iberoamericana de Filosofia, Madrid, Trotta, pp. 153-176.

Sarnitz, A., 2013, "La arquitectura de Wittgenstein. Reconstrucción de una idea edificada", A. Rubio (trad.), en J. Marrades (ed.), Wittgenstein: Arte y Filosofía, Madrid, Plaza y Valdés, pp. 277-311.

Spinoza, B., 2000, Ética demostrada según el orden geométrico, A. Domínguez (trad.), Madrid, Trotta.

Stenius, E., 1960, Wittgenstein's Tractatus. A Critical Exposition Of Its Man Lines Of Thought, Oxford, Basil Blackwell.

Villoro, L., 1975, "Lo indecible en el Tractatus", Critica. Revista Hispanoamericana de filosofia, VII/19, pp. 5-39.

Valcárcel, A., 1998, Ética contra estética, Barcelona, Crítica.

Waugh, A., 2009, La familia Wittgenstein, G. Páez Irrací (trad.), Barcelona, Lumen.

Zan, J. de, 2002, Panorama de la ética continental contemporánea, Madrid, Akal, pp. 29-40. 